\title{
Control and Governance of Public Companies: Case of Public Establishments in Morocco
}

\author{
Astitene Dounya, Sror Mbarek \\ Faculty of Economics and Management, Ibn Tofail University Kenitra, "Management, Finance \& Accounting" Research Laboratory, Kenitra, \\ Morocco
}

\author{
Email address: \\ D.astiten@poste.ma (A. Dounya),mbareksror@gmail.com (S. Mbarek)
}

\section{To cite this article:}

Astitene Dounya, Sror Mbarek. Control and Governance of Public Companies: Case of Public Establishments in Morocco. Journal of Public Policy and Administration. Vol. 5, No. 2, 2021, pp. 53-61. doi: 10.11648/j.jppa.20210502.14

Received: February 23, 2021; Accepted: May 13, 2021; Published: June 4, 2021

\begin{abstract}
Control in a broad sense is often defined as a tool for good governance within the company, particularly that belonging to the public sphere, where the concept of control is often synonymous with a structural or even regulatory obligation to be observed, particularly at the level of the public structure. The purpose of this article is to highlight, the main attributes defining the mode of control within public structures, particularly in the Moroccan context. Also, it is proposed to examine the positioning of internal control at the level of the national and international context and its evolution within the public entity in Morocco. So, a first section is devoted to a clarification of the concept of governance and a lever value creation. At the second, the context related to internal control at the level of public organizations in Morocco is presented. Then, a close look is taken at the concept of Control as an elementary axis of enlightened and performance-oriented governance. On another level, with regard to the public structure in Morocco, a presentation of the evolution of the concept is exposed, complemented in the last part by a review of the regulatory and organizational framework governing the management of the public portfolio.
\end{abstract}

Keywords: Public, Internal Control, Governance, Performance, Regulatory

\section{Introduction}

The generation of value [1] is certainly an objective which remains at the origin of any company creation justifying the injection of funds and resources resulting a priori from a financial package aiming at an expected return on investment. The company in the global sense of the term is thus part of a global vision of achieving an ultimate objective which is the creation of wealth.

After having clearly defined its strategic framework, which aims to achieve performance in the economic sense of the term, the company designs its action plan and the monitoring system to ensure that its activity is steered in a value-creating dynamic. In this conception of things and considering a changing framework of the company naturally marked by internal and external evolutions, the company's operating plan thus requires regulation, revision and control throughout its life cycle.

On the other hand, we propose to fix as a fundamental apprehension of the public structure as being a structure assimilated to a firm in the didactic sense of the term, which is supposed to be thus exposed to the same constraints and concern for performance as a firm from the private sector.

Now, the theorists of the "public service" current consider the character of general interest by being at the origin a priori of the creation of entities producing services rendered to the public belonging to the State, without being interested in the notion of profitability of the firm in terms of the financial gain generated by its activity.

Therefore, it is necessary to clarify that this concept has lost its value, by admitting that in order to guarantee the continuity of public service, it would be necessary to think about the economic viability of public organizations, which are entities that consume significant resources by being designated as executive bodies of the country's economic and social policies. However, they are now bound by an obligation of result and must keep their places in a market where competitiveness is often in full swing. So many imperatives are therefore imposed on the public enterprise to achieve its objectives, while having to comply with the 
guidelines and standards established by the State.

In other words, it is necessary to understand the governance of the public enterprise in a perspective of rational management, which is supposed to tend towards efficiency in terms of resource management, hence the crucial importance of concept of control [2] as an integral part of good governance. It is within the framework of this perspective that our main research issue falls:

To what extent is control, especially that exercised internally, translated into a tool for good governance of public enterprises?

In order to respond to the present problem, we propose to put in the foreground the main concepts related to governance, in particular that in connection with the public sphere, in the second place we will highlight the concept of control by scrutinizing in particularly the landscape of the regulatory and organizational framework governing internal control at the public sector level in Morocco.

\section{Governance, a Fundamental Issue at the International and National Levels}

\subsection{Definition and Concept}

The context of globalization and market growth, and the resurgence of financial scandals have strongly motivated the need to strengthen and formalize the rules of vigilance by international and national supervisory and regulatory authorities, corporate governance and control bodies. As a result, over the last decade we have witnessed a series of laws and regulations designed to strengthen the governance and control models of the management practices and standards of companies operating in national and international economic circuits, where the following are the main examples. The OECD ${ }^{1}$ Principles of Corporate Governance approved in 1999 by the ministers of the OECD countries, which have since become an international reference for government officials, investors, companies and other stakeholders. The principles and standards of ethics established by international organizations such as Transparency International; the Sarbanes-Oxley Act, a U.S. law dating back to 2002 set up following repeated financial scandals. The latter sets requirements for corporate governance and extends the civil and criminal liability of the governing bodies of listed companies in the United States. Finally, we can also mention the Basel Committee, which enacts and regularly updates the prudential banking standards reference framework.

At the national level, governance is regulated both explicitly and implicitly, in particular through the labor code, the penal code, the commercial code. The law on public companies was limited with especially the banking law, such

1 The Organization for Economic Co-operation and Development (OECD) is a forum in which 30 market democracies work together to address the economic, social and governance challenges posed by an increasingly globalized economy, These 30 economies account for $75 \%$ of world trade. as the circulars of the financial communication and the ethical rules governing information within listed companies. the circular of Bank Al-Maghrib on the internal control of credit institutions and similar organizations and its directives on governance and the compliance function, and the Moroccan Code of Good Practices in Corporate Governance drawn up in 2008 [12] by the National Commission for Corporate Governance, created in 2007. At the public sector level, the regulatory framework that governs state action in the area of governance is mainly referred to, in particular Law 69-00 governing the financial control of public structures.

As a result, in the face of the natural evolution of the importance of governance within the company, there has been a growing awareness of the undeniable impact of governance on value creation, which intrinsically refers to the economic benefits provided to the owners and all stakeholders of the company.

\subsection{Governance in the Public Sphere}

In attempting to merge the economic and political scope of the notion of governance, we can define governance as the set of organizational standards, measures and systems put in place to ensure the proper functioning of any organization. According to the OECD, governance is defined as "the exercise of political power and control in the administration of the resources of the company for the purposes of economic and social development". On the other hand, in order to ensure that the interests of its owners are safeguarded and respected, the company is governed by a governance system that is designed and implemented through operating rules backed by steering and control mechanisms. The supreme authority of which is often a board of directors that is responsible for the company's accountability to its shareholders.

On the side of the public structure, governance occupies a crucial place in view of the importance that the management of the collective patrimony requires for the so-called shareholder state. Considering the agency relationship that exists between the states designated as the "principal" and the manager of public enterprises qualified as an "agent" by virtue of the agency theory dissecting the said relationship [13].

In this sense, we shall evoke the notion of corporate governance, which globally designates the different rules of management of the firm in terms of the management of the firm and in terms of the relations that exist between management and shareholders. In particular, these rules have a direct influence on the management and control of the company.

Corporate governance, taking into account the public dimension, revolves around three main vectors; namely, guidance through the setting of clear objectives that reconcile sectoral and economic development policies, and the redefinition of management principles that support continuous improvement management based on international management standards. Finally, in addition to the first two 
elements, the evaluation and control component is relayed as an indispensable support to guarantee the achievement of the expected objectives through, in particular, a continuous verification of the performance achieved throughout the company's life cycle.

In this sense, elements of support for good governance have been put in place to guide the actions of Public Establishments and Enterprises towards the achievement of optimal efficiency in the context of the objectives assigned to them. In this regard, the Moroccan code of good corporate governance practices is a reference framework consolidating good practices developed by a national commission inspired by an international benchmark and the principles of corporate governance as formulated by the OECD. The said code is part of an evolving process of governance aimed at instilling a management method to improve the performance, competitiveness and growth of the portfolio of Moroccan companies. This includes the specific set of EPEs, which are in themselves an essential driving force for the economic and social development of the country. The development of the performance of the EPEs is, in fact, part of the main strategic orientations of the Moroccan State given their actual and potential contribution to the realization of the country's structuring projects.

Thus, the EPEs are constantly challenged to ensure the proper deployment of their resources allocated to them in compliance with the guidelines set by the State while accepting free competition with private sector companies because of the cohabitation of the two sectors in a common market. This is gradually taking place under the effect of the gradual withdrawal of the protective state, which is going hand in hand with the continuous reduction of the benefits they derive from the PES sector. This calls for more autonomy and responsibility for the management and prosperity of the public organization, particularly those belonging to the market sector obeying the same rule of market supply and demand as those from the private sector.

Thus recognizing the specificity of the public sphere and the social and economic commitments carried by PEEs. The shareholder state is obliged to develop its system of surveillance and protection against all risks that could hinder their development, on which the country's economy and its growth projections depend heavily.

In short, by being marked by developments at the national and international levels while striving to take advantage of the benchmark of good practices, The OECD guidelines and by considering the findings of audit and control missions carried out at the level of EPEs, the State is thus aware of the need to work on restructuring projects to ensure a dynamic and real competitiveness of EPEs. In this regard, the draft law on governance and financial control is particularly noteworthy.

The bill essentially aims to strengthen the governance and control mechanism of the EEPs in a logic of efficiency and performance improvement by focusing on the fundamental elements: timeliness, regularity, reliability and performance while striving to align with best practices and international standards. The State aims to play the role of strategist, shareholder and supporter without neglecting its drastic mission as controller.

\subsection{Control, a Support for Governance and a Lever for Value Creation}

Considering all the economic and social challenges facing public institutions, while being concerned to have institutions that develop under the best conditions of security and good governance [10]. The state is constantly working to strengthen its control system and to ensure that the structures that support the country's economy, particularly those belonging to the public sector, are brought into line with the law.

Indeed, this strategy of the State is often translated at the level of the public company by a reinforcemt of its internal control system involving a compliance of its actions, processes, procedures and reports with respect to internal and external actors, in compliance with the laws and regulations in force. This will help to ensure the foundations of good governance and preserve the company's long-term viability, which must always be in line with best management practices In other words, it is a mode of governance based on interacting bodies and actors that enables the implementation of the internal control systems necessary for the security and compliance of the activities carried out by the company. These bodies [6], such as the Board of Directors, the Audit Committee, the Inspection and Audit function, and the Permanent Control function, are responsible in particular for ensuring compliance with the legal and regulatory requirements governing the company's operations and the conduct of its business. Particularly with regard to regulatory and external control bodies such as Bank Al-Maghrib, the Audit Office and the Ministry of Finance.

It is certainly difficult to apprehend a direct cause-andeffect relationship between the concept of control and the creation of value [8] within the company. Paradoxically, it is recognized that the interest of internal control has historically focused on the control of expenses, which presents an element of contribution to improving the level of wealth production by being closely linked to the notion of profit margin and by acting mainly on the notion of cost.

The first approach to internal control was officially introduced at the level of the organizational framework on an international scale in 1985 when the COSO framework was set up following various financial scandals that affected organizations with a strong economic contribution on a global scale. This approach has been the subject of numerous publications and is even considered as a textbook case rich in lessons in terms of business management on a political and economic level. This event has motivated the consecration of a regulatory arsenal that essentially aims to cover financial risks, notably through the Sarbane-Oxley Act of July 30, 2002 in the United States and the law on the requirement to publish reports on internal control systems, which is close to the general principles of the $\mathrm{COSO}^{2}$.

$2 \mathrm{COSO}$ is an internal control framework defined by the Committee of 
As a result of these changes in the international financial marketplace, the concept of internal control has taken on an important role at the level of organizations, which have become more concerned with ensuring control over the reliability of the information system and compliance with the laws and regulations that govern them, as well as the achievement of the objectives set by the company. Indeed, a number of companies highlight their internal control systems as a reasonable assurance that their objectives will be achieved, particularly in terms of development and performance control, which is often synonymous with a guarantee of the company's long-term viability.

It is thus a tool for the company's progression towards the achievement of its value creation objectives, something that has been formally and explicitly formulated at the level of the COSO reference framework as well as at the level of ISO $3100^{3}$ as a reference framework related to risk management. This makes it possible to reveal the control activity as the driving force behind the creation of policies and procedures that are defined and deployed in order to ensure the implementation and effective application of the risk management system within the company.

The COSOS explains, to a certain extent, the methodology of internal control by describing it as a tool for controlling activities and the associated risks. It should be stressed that this is not the only reference framework that deals with the concept of internal control; however, it appears that it is widely used, particularly in the management of risks related to the public domain.

The COSO repository is aimed at all levels of the organization while being broken down into four main operational objectives:

1) Compliance with laws, regulations, contracts;

2) The protection of the patrimony, in a today's enlarged meaning which includes, in addition to the assets of the organization, its agents and its image;

3) The reliability and integrity of financial and operational information (reliable and verifiable, comprehensive, relevant, available);

4) Effectiveness and efficiency of operations.

In other words, internal control is an integral part of a company's operational management system as well as the risk management mechanism referred to primarily in the COSO framework. Indeed, this reference framework integrates internal control and presents a model of it and a "solid" management tool in itself.

On the other hand, internal control is defined in the book entitled Internal Control Integrated Framework ${ }^{4}$, which is a

Sponsoring Organizations of the Treadway Commission. It is used in particular in the context of the implementation of the provisions of the Sarbanes-Oxley, SOX or Financial Security Act (LSF) for companies subject to US or French law respectively. Since 2002, the initial COSO 1 standard has evolved into a second body of standards known as COSO 2 .

3 International norm for organizations in the risk management.

4 This framework has proved its worth and forms the basis of rules, regulations and laws currently in force and remains applicable as an internal control framework. repository of rules, regulations and laws currently in force and remains applicable as a reference framework for internal control.

In addition, the overall effectiveness of internal control is often said to be conditioned by an adequate assessment of the strategic and operational risks facing the organization. However, in order to be able to claim a robust internal control system that acts with optimum effectiveness for the benefit of the company. It is necessary to rely in particular on an appropriate control environment, namely a policy of commitment designed to promote ethical values supported by the company's management; supervisory bodies (Board of Directors or Supervisory Board) with the necessary independence to monitor the effectiveness of the internal control system, structures, powers and responsibilities clearly defined by management to achieve the objectives set, and adequate competencies without neglecting the duty to report on the achievement of objectives.

In sum, COSO, as a conceptual standard framework provides the necessary tools to enable all interested parties (directors, officers, managers and control experts) to have assurance of a structural framework for an organization under control.

Generally speaking, internal control [9] can be described as the set of measures contributing to the control of the risks to which the company is exposed on both the internal and external fronts. In other words, the essence of control lies in the protection and safeguarding of assets and the quality of information, on the one hand, and the application of management instructions aimed at creating an environment that promotes the improvement of the company's performance, on the other.

\section{Public Internal Control Within the company in Morocco}

\subsection{The Enterprises and Public Establishments Sector in Morocco (EPE)}

In order to create a real source of value by guaranteeing the security and profitability of public assets, the State has developed a portfolio of public companies and institutions that generate social and economic value for the country. The public sector operates in various strategic sectors of activity that constitute an essential economic lever. The portfolio comprises 212 public establishments and 44 public enterprises. Some of these EPEs have subsidiaries or holdings totaling 442 units, of which 236 are majority-owned (direct and indirect public shareholding greater than or equal to 50\%) and 206 are minority-owned (direct and indirect public shareholding less than 50\%) [11].

These are companies with large-scale investment programs, which are strongly supported by the State because of their economic and social importance for the country. Indeed, according to the report on reports accompanying the draft finance laws for the year 2019, the level of investments made in 2016 by FIEs reached $72,675 \mathrm{MDH}$, thus recording an 
average annual growth rate of 1\% over the period 2010-2016.

In sum, public enterprises play a vital role in supporting the national economy by being, among other things, a major lever of government programs. Their impacts are also spread out over the development of the private sector by positioning themselves as suppliers, sponsors, clients and even partners of weight towards the private sector. In addition, the importance of the role of public enterprise in the development of the private sector is often recognized, even limiting the entry and development of private enterprises.

Improving performance remains a major challenge for EPEs, which continually encourages the government to invest more in a reform dynamic relating to the modes of governance of the public sector. In this context, a great deal of work has been done to improve the effectiveness of public action, in this case in terms of monitoring and supervising the performance of the EPEs, which is reflected in a control mechanism put in place by the State.

Before addressing the practical aspect of control as exercised at the level of public structures, it would be useful to understand the notion of control and its evolution within the public entity.

With reference to the public dimension, the ultimate purpose of control is to direct the public organization towards the achievement of its mission of general interest. In this sense, following a chronological analysis of the evolution of the control exercised over the EPEs, one speaks a priori of a financial control that is globally focused on the regularity and conformity of the EPEs. with the regulations, after having largely presented its limits in relation to the vision of the State, Which aims to build efficient and competitive institutions, was the subject of a structural overhaul project in 2016, with the aim of associating other objectives, which can be summarized as supporting and improving the performance of public organizations. Also with a view to overcoming the shortcomings revealed earlier, by moving towards a resultsbased approach and making the best use of State intervention through its supervisory bodies.

\subsection{Characteristics of Control Within EPE Moroccan Context}

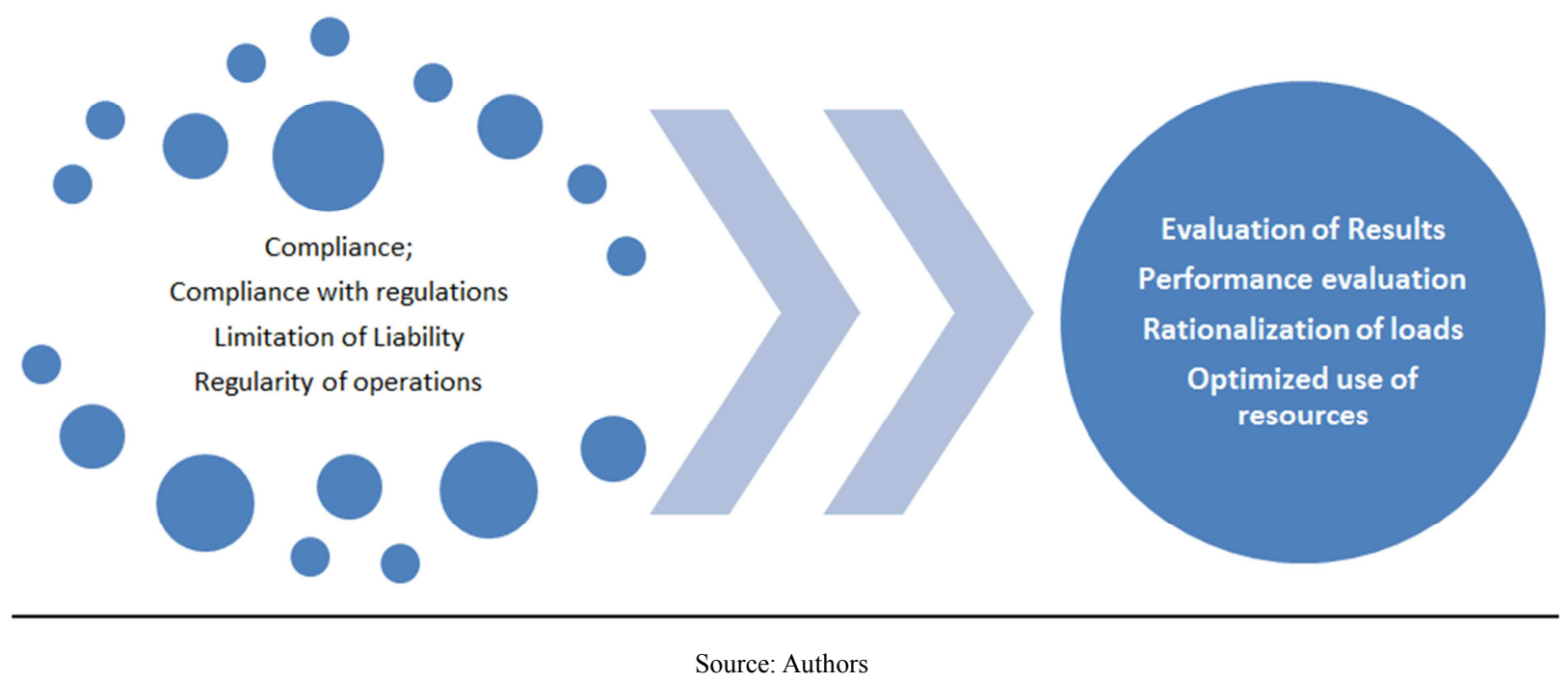

Figure 1. Evolution of financial control within EPEs.

Indeed, the financial control project proposes to support the economic steering programs of the EPEs by taking them to new levels in terms of re-accountability and transparency. In addition to its role as a regulatory compliance controller, the State, through its financial control system [2], is planning to play a role in guiding and supporting the EPEs, which will enable performance to be assessed and sector-related risk prevention to be carried out through a clear definition of objectives and responsibilities. The control exercised by the State is designed to complement the internal control system put in place by the EPE, which is in turn supplemented by the management control system, whose main mission is to ensure reliable and relevant feedback of information that will allow, among other things, the optimization and better orientation of internal control actions.

In this regard, considering the economic, social and financial stakes that characterize PEEs, several programs aim to support the development of PEEs on the one hand, and to regulate and monitor their performance on the other. In this regard, several audit missions have covered almost all sectors of activity, with 71 audits carried out during the period 20002016, with the primary objective of limiting the scope for error and potential drift to the standards and regulatory requirements in place. In short, the public organization is subject to a multiplicity of controls, which are exercised internally and implemented by the company's own management, as well as externally through missions carried out by external supervisory authorities.

In this vein, the new draft law on financial control finds its essence in the new vision of evaluation that focuses on the notion of EPE control by becoming essentially focused on the performance of the public enterprise. At the most 
concrete level, it is a question of setting up a control level to be applied according to the level of maturity of the EPE, whose maturity is assessed according to several indicators; in this case, its management and monitoring mode developed internally. In other words, the control method must be adapted to the company's information and management system, in particular by integrating the risk prevention aspect. It is thus necessary to assess the quality of the EEP's governance system. Which remains strongly correlated to its level of performance as a direct result of its internally developed management mode, beyond its role of measuring regularity and compliance. Enabling it to detect and prevent irregularities, fraud and negligence, internal control contributes to the improvement of the company's economic performance by highlighting a direct relationship between the control mechanism and the company's financial performance, by acting mainly on the reliability and relevance of the elements related to invoicing, collection, cash management, investment, etc. In short, internal control contributes to the improvement of the company's economic performance; or a broad area of financial optimization, in which internal control plays an essential role. This has been the subject of much academic and practical research in the field of corporate financial performance, while taking a critical look at the notion of internal control in the "strict" sense of the term, which is often synonymous with compliance control, particularly with regard to the adequacy of public-sector structures.

In the same vein, the control of public organization has been the subject of several criticisms, particularly within the framework of the work of the OECD, of which Morocco is a member, thus encouraging the development of internal control and management control and, in return, reducing the external control exercised by the State. Which control must be increasingly targeted and modulated according to the level of performance of the public enterprise in terms of governance; by adopting criteria for the segmentation of EPEs that justify the firm's eligibility for a given type of control. The objective is to optimize and better direct public intervention at the level of the EPEs.

In view of the Moroccan context, all public structures are a priori part of the target subject to the draft new financial control law, except those in liquidation. The new law provides for four categories of financial control: a priori financial control; accompanying financial control; a posteriori financial control; and contractual financial control. These controls will make it possible to ensure the appropriateness, regularity, reliability and assessment of the economic and financial performance and risks of the public company.

It is therefore appropriate to measure the causal relationship between performance and the dimension of control in general and internal control in specific terms in order to be able to claim real support in the economic development of the public enterprise. Given that control constitutes a basis for steering and directing public organizations towards the achievement of their assigned objectives while at the same time limiting their potential opportunism.

In short, we consider control to be synonymous with a system that guarantees the factual achievement of the expected and fixed performance of the public company, without forgetting that it is a fact that remains strongly conditioned by the implementation of the prerequisites and determinants of optimal and efficient control [7].

In this sense, we will mention the regulatory reference system, which is of crucial importance in the sphere of EPEs, and which provides a framework for the management of public affairs. It is important to recall in this respect the major objective historically assigned to the public structure, which consists of a necessity or even an obligation to comply with the laws and regulations governing its mode of governance.

\section{Review of the Organizational and Regulatory Referential of Internal Control within EPEs}

\subsection{Regulatory and Organizational Control Framework Put in Place Within EPEs}

The regulatory framework linked to the concept of internal control, as formulated and set out in the relevant texts, is set out below. In addition, a point of interest will be made on other publications of national scope that are related to the field of corporate governance, particularly those belonging to the public sector.

Therefore, we based ourselves on a purely exploratory approach in the field through a documentary study of the various regulatory and organizational references which addressed the concept of internal control at the level of public structures [7]; this allowed us to clarify the positioning of internal control in line with governance of public organizations.

(*) .... "The implementation of an internal control system ensures preventive control of the organization's operations. Its implementation involves a set of detailed and precise procedures for each of the organization's operations. For each of the operations covered by the procedures, one or more general control principles are applied to ensure compliance with the objectives of internal control. The control techniques may themselves be adapted to the specific case of each body to take account of its particular features. Internal control is based on procedures covering all recurring operations. These operations may be dealt with, provided that they are adapted to them, according to the means at the disposal of the body. To ensure the effective nature of risk prevention, the principle of segregation of duties prevents a single person from carrying out the various stages of the procedure. For example, admitting that the same person selects the merchandise, places the order, receives it and pays for it, gives no assurance of avoiding the risks of errors in selection, erroneous accounting transcription, undue payment, or even misappropriation, nor of detecting the 
effects thereof. It is therefore important that these different operations are carried out by different actors, according to precise and predefined procedures, and whose execution can be verified by third parties. Moreover, these actors must be judged on different efficiency criteria that ensure their independence in carrying out the tasks entrusted to them. Operations must be handled within the framework of organized and systematic procedures".

Table 1. Inclusion of the concept of internal control in the regulations governing the governance of Moroccan EPEs.

\begin{tabular}{|c|c|c|c|c|}
\hline Texts governing public enterprises & $\begin{array}{l}\text { Current Internal } \\
\text { Control } \\
\text { Terminology }\end{array}$ & $\begin{array}{l}\text { Defined } \\
\text { concept }\end{array}$ & $\begin{array}{l}\text { By defining the } \\
\text { installation } \\
\text { mode }\end{array}$ & $\begin{array}{l}\text { By defining the opportunities related to its } \\
\text { deployment }\end{array}$ \\
\hline $\begin{array}{l}\text { Dahir } n^{\circ} 1-03-195 \text { of Ramadan } 16,1424 \\
(11 / 11 / 2003) \text { promulgating Law } n^{\circ} 69-00 \text { relating to } \\
\text { the financial control of the State over public } \\
\text { enterprises and other organizations. BO. } N^{\circ} 5170 \text { of } \\
18 / 12 / 2003 \text {. }\end{array}$ & Yes & No & No & $\begin{array}{l}\text { Yes, indirectly: it is a differentiation tool to access a } \\
\text { level of control by the State within the framework of } \\
\text { the financial control exercised by the State. }\end{array}$ \\
\hline $\begin{array}{l}\text { Order of the Minister of Finance and Privatization } \\
\text { No. } 1549-05 \text { of } 18 \text { kaada } 1426 \text { (December } 20 \text {, } \\
\text { 2005) establishing the management instruments of } \\
\text { public establishments eligible for the accompanying } \\
\text { audit. }\end{array}$ & Yes & Yes & Yes & Yes $(*)$ \\
\hline $\begin{array}{l}\text { Moroccan code of good governance practices for } \\
\text { companies and public institutions. }\end{array}$ & Yes & No & No & $\begin{array}{l}\text { Yes, indirectly, by presenting it as a means of } \\
\text { assessing the management of the management bodies } \\
\text { of the EPEs through the quality of internal control, } \\
\text { budgetary achievements and on the basis of criteria } \\
\text { performance as well, in order to add value to the EPE } \\
\text { activity and help it achieve its objectives and assess } \\
\text { the compliance of the organization's management to } \\
\text { the mission and objectives assigned to it, as well as } \\
\text { its performance economic and financial aspects of the } \\
\text { said organization. }\end{array}$ \\
\hline $\begin{array}{l}\text { Decree no. 2-06-175 of } 27 \text { safar } 1427 \text { (March } 28 \text {, } \\
\text { 2006) establishing the list of public establishments } \\
\text { subject to accompanying supervision }\end{array}$ & No & No & No & No \\
\hline $\begin{array}{l}\text { Methodological guide for the contractualization of } \\
\text { relations between the State and companies and } \\
\text { public institutions }\end{array}$ & Yes & No & No & $\begin{array}{l}\text { Yes, in terms of the potential for change the type of } \\
\text { control applicable to the EPE }\end{array}$ \\
\hline $\begin{array}{l}\text { New Draft Law on State Financial Control over } \\
\text { Public Enterprises and Other Bodies }\end{array}$ & Yes & Yes & No & $\begin{array}{l}\text { Yes, as a tool for assessing the mode of governance } \\
\text { of the EPE }\end{array}$ \\
\hline
\end{tabular}

Source: Authors

\subsection{Analytical Review of the Regulatory and Organizational Framework of the Concept of Control at the EPEs Level}

An analysis of the texts presented above shows that the place occupied by the concept of internal control in the regulatory and organizational framework governing the operation and management of internal control in EPEs remains in an embryonic state.

Table 2. The distribution of EPEs by type of control is as follows At the end of 2017.

\begin{tabular}{ll}
\hline Type of control & EPE Numbers \\
\hline Preliminary control & 208 \\
Accompanying control & 24 \\
Conventional control & 34 \\
Specific control & 21 \\
\hline
\end{tabular}

Source: Authors

At the level of the so-called regulatory framework, the concept of internal control is considered to be a factor in the classification of EPEs in relation to the company's level of maturity in terms of governance. This is essentially the new draft of the new law on financial control, without dwelling on the foundations and components of internal control, particularly in terms of the objectives and methodology for the implementation of internal control within the public organization. For example, submission to the accompanying audit is conditional on the implementation of an internal control system.

In view of the table below, it is easy to see the dominance of a priori control at the level of the portfolio of EPEs, which is indicative to some extent of the level of maturity and development of the mode of governance established at the EPE level; taking into consideration the criteria for classifying EPEs in relation to the mode of internal governance of the EPE.

On the other hand, in other non-regulatory publications such as the Code of Good Practices, internal control is included generically as a basic element of good governance and a key internal management tool for assessing the quality of the company's management.

In general, internal control is generally referred to in a summary and indirect manner in the reference framework presented and used as a reference base in this document.

Given the regulatory nature of the management framework 
governing the EPE, which is often assessed on the basis of compliance with the laws and regulations and procedures in force, it is important to note the impact of the regulatory and procedural framework on the internal management model at the EPE level.

A number of publications have been examined on the official websites of the Ministry of Finance in charge of managing the EPE portfolio, in particular through the Directorate of Public Enterprises and Privatization, in order to understand the level of popularization of the concept in these publications, and an indirect approach to the concept of internal control has emerged, without, however, being part of the detailed and/or explicit model of the guidelines and methodology of the consistency of internal control.

In the same vein, by scrutinizing a number of publications of the Court of Auditors' reports relating to the field of EPEs, it was generally raised that internal control is designated as an instrument for the strategic steering of the company without specifying the details of its implementation on the structural and functional level within the company.

In this sense, it was formally pointed out in the report of the Court of Auditors on the sector of public establishments and enterprises in Morocco [4] that "One of the main contributions of the reform of the State's financial control of public enterprises, which is the subject of law $n^{\circ} 69-00$ [5], which came into force in 2003, was the introduction of a typology of controls based on criteria related to the quality of governance and management information systems with the aim of migrating most public companies from an a priori control to an a posteriori control based on results and performance.

All these studies agree that the implementation of internal control as an instrument of good governance and corporate performance management must be based on the following elements:

1. The generalization of reporting at all levels of the company;

2. Communicating and raising awareness among all personnel of the importance of control in improving the company's performance in order to guarantee a collaborative approach by the personnel who adhere to the internal control approach implemented;

3. Systematize internal control missions by assigning clearly identifiable and understandable objectives and procedures at all levels of the company;

4. Ensure a system of access to the information system

In addition to these so-called key elements for the success of an internal control system at the level of the company as a whole, it is worth noting a major element of capital importance consisting of support for the EPEs, in particular for the implementation of internal control systems, notably via a regulatory and organizational reference framework that takes into account the specific features of the public structure and its sensitivity to the aspect of compliance with laws and regulations.

In other words, it is recognized that the behavior of public companies is strongly influenced and guided to a large extent by government policies as well as the laws and regulations governing their activities and establishing their management methods. As a result, the effective implementation of an internal control system remains highly dependent on the regulatory and procedural shaping that sets the standards and methods of internal control within the public company.

\section{Conclusion}

Engaging in an internal control process is doubly useful in order to contribute to value creation within the company as well as to comply with its regulatory obligations to stakeholders, particularly for public companies.

To a certain extent, this demonstrates the general interest of such a value-generating investment in the medium and long term for the public company by being part of an approach based on sustainability and continuous improvement.

This research shows the capital importance of the regulatory and procedural reference framework for the effective implementation of the internal control system in a public company.

In this sense, it is recommended that this research be followed up with an experimental analysis targeting a sample of public enterprises to allow a better appreciation of the positioning and profitability of auditing within public organizations, particularly those making up the portfolio of EPEs operating in the public sector with high added value. Through this study, we have been able to provide factual answers to the following main questions:

1) Effective existence of an internal control system to serve the performance of the public company;

2) The perception of control at the level of the public company;

3) The constituent elements of this control at the level of the public structure (permanent control, audit \& risk management, periodic audit, inspection);

4) The organizational positioning of internal control at the level of the public company;

5) The main missions and objectives of the control defined? Popularized?

6) The application of the internal control system at the level of the public company's subsidiaries;

7) The establishment of links between the main management control elements, namely: management control, strategic management and internal control.

8) Establishment of governance bodies Internal control prevails as a tool for the strategic management of public companies.

To sum up, these are all questions and issues of interest in the field of internal control that are acutely apparent and require, in our opinion, an in-depth understanding by transposing them to the level of the public company, taking into account the vital importance of the portfolio of EPEs in the economic fabric of the country. 


\section{References}

[1] ASSAAD IDRISSI M. \& OUDDA Y. TAOUAB. O (2020). The practices of the management control system at the level of the public sector: The case of Moroccan public administrations. International Review of Management Sciences, Number 6 / Volume 3: number 1 "pp: 302-326.

[2] BATAC, J. CARASSUS, D. MAUREL, C. (2009), "Evolution of the internal control standard in the local public context". Finance Contrôle Stratégie.

[3] Brealey, R. A. et Myers, S. C. (2013): Principles of corporate finance, McGraw-Hill, 11e éd., Global Edition, Buchanan (1972). Public Choice Theory: Work by Buchanan.

[4] Court of Auditors (2016), Report of the Court of Auditors entitled "the public enterprise sector in Morocco: Strategic anchoring and governance".

[5] Dahir No. 1-03-195 of Ramadan 16, 1424 (2003), "Law No. 69-00 relating to State financial control of public enterprises and other bodies". BO. $\mathrm{N}^{\circ} 5170$ of 18/12/2003.

[6] Directorate of Public Enterprises and Establishments and Privatization (DEPP). (2019), Presentation note Draft law on governance and State financial control on public establishments and other financial control bodies.
[7] ERREIMI, M., \& KADOURI, A. (2020). An overview of the risk assessment and analysis of the relationship between the control environment, the potential for fraud and the internal control objectives. Review of control, accounting and auditing (revue CCA).

[8] Grégory Denglos (2007). Creation of value and corporate governance. Do the shareholder's requirements conflict with the "social" interest. La Revue des Sciences de Gestion (n ${ }^{\circ}$ 224-225), pages 103 to 112 .

[9] International Organization for Standardization (2018), ISO 31000 "Risk Management".

[10] John Pitseys (2010). The Concept of Governance, Interdisciplinary Journal of Legal Studies 2 (Volume 65), p 207 to 228 .

[11] Ministry of Finance (2018), "Report on PEAs Accompanying the 2019 Finance Bill".

[12] National Commission on Corporate Governance (2008), "Moroccan Code of Good Practices in Corporate Governance".

[13] Michael C. Jensen and William H. Meckling (1976). Theory of the firm: Managerial behavior, agency costs and ownership structure. Journal of Financial Economics, vol. 3, no 4, p. 308. 